This is an electronic reprint of the original article. This reprint may differ from the original in pagination and typographic detail.

\author{
Author(s): Torppa, Minna; Tolvanen, Asko; Poikkeus, Anna-Maija; Eklund, Kenneth; Lerkkanen, \\ Marja-Kristiina; Leskinen, Esko; Lyytinen, Heikki
}

Title: $\quad$ Reading development subtypes and their early characteristics

Year: $\quad 2007$

Version:

Please cite the original version:

Torppa, M., Tolvanen, A., Poikkeus, A.-M., Eklund, K., Lerkkanen, M.-K., Leskinen, E., \& Lyytinen, H. (2007). Reading development subtypes and their early characteristics. Annals of Dyslexia, 57(1), 3-32. https://doi.org/10.1007/s11881-007-0003-0

All material supplied via JYX is protected by copyright and other intellectual property rights, and duplication or sale of all or part of any of the repository collections is not permitted, except that material may be duplicated by you for your research use or educational purposes in electronic or print form. You must obtain permission for any other use. Electronic or print copies may not be offered, whether for sale or otherwise to anyone who is not an authorised user. 
Reading Development Subtypes and Their Early Characteristics

Minna Torppa ${ }^{1}$, Asko Tolvanen ${ }^{1}$, Anna-Maija Poikkeus ${ }^{2}$, Kenneth Eklund ${ }^{1}$, Marja-Kristiina Lerkkanen $^{2}$, Esko Leskinen ${ }^{3}$, and Heikki Lyytinen ${ }^{1}$

\footnotetext{
${ }^{1}$ Department of Psychology, University of Jyväskylä

${ }^{2}$ Department of Teacher Education, University of Jyväskylä

${ }^{3}$ Department of Mathematics and Statistics, University of Jyväskylä
}

Torppa, M., Tolvanen, A., Poikkeus, A-M. Eklund, K., Lerkkanen, M-K., Leskinen, E., \& Lyytinen, H. (2007). Reading development subtypes and their early characteristics. Annals of Dyslexia, 57, 3-32. 


\begin{abstract}
Present findings are drawn from the Jyväskylä Longitudinal Study of Dyslexia (JLD) in which about 100 children with familial risk of dyslexia and 100 control children have been followed from birth. In this paper we report data on reading development of the JLD children and their classmates, a total of 1750 children from four measurement points during the first two school years. In the total sample we examined whether heterogeneous developmental paths can be identified based on profiles of 1st through 2nd grade word recognition and reading comprehension skills after controlling for the classroom membership effect. Secondly we studied what kind of early language and literacy skill profiles and reading experiences characterize the children in the follow-up with differing reading development. Our analyses included comparisons of the reading development of the JLD children with and without familial risk for dyslexia. The mixture modelling procedure resulted in five reading subtypes: (1) 'Poor readers' with poor skills in both word recognition and reading comprehension, (2) 'Slow readers' with somewhat below average word recognition combined with faster than average growth in reading comprehension, (3) 'Poor comprehenders' with average word recognition combined with slower than average reading comprehension development, (4) 'Average readers' with average skills in both word recognition and reading comprehension, and (5) 'Good readers' with high level of performance in both reading skills. The children with familial risk for dyslexia performed on average at a lower level in all reading tasks than both their classmates and controls and they were over-represented in the reading subtypes with deficient fluent word recognition. Differences were found in the early language and literacy skill development of the reading subtypes.
\end{abstract}




\section{Reading Development Subtypes and Their Early Characteristics}

\section{Introduction}

Learning to read is one of the most important goals of the first school years. The 'simple view of reading' (Gough \& Tunmer, 1986; Tunmer \& Hoover, 1992) defines reading ability as a function of decoding and comprehension skills, but at the early phases of learning to read, word recognition and reading comprehension are difficult to separate. After children become more fluent readers, reading comprehension emerges more clearly as a closely related but separate skill from basic word recognition ability (e.g., Catts, Hogan, \& Fey, 2003; Nation, 2005; Storch \& Whitehurst, 2002). At the level of children's reading skill profiles the relation between these two is manifested in findings of four reading subtypes; children without reading difficulties, children with primary problems in word recognition (i.e., those diagnosed with dyslexia), children with primary problems in comprehension (often referred to as poor comprehenders or as having hyperlexia), and children with both word recognition and comprehension difficulties (often referred to as slow learners, garden-variety poor readers or as having language-learning disabilities, LLD) (e.g., Catts et al., 2003; Leach, Scarborough, \& Rescorla, 2003; Nation, Clarke, Marshall, \& Durand, 2004;

Shankweiler et al., 1999). The prevalence of the reading difficulty subtypes has varied greatly depending on the age and characteristics of the sample. Children with reading difficulties most typically show difficulties in word recognition, and the children for whom poor comprehension skills combine with average word recognition comprise only about 6-15\% of the poor readers (Catts et al., 2003, Leach et al., 2003; Nation et al., 2004; Shankweiler et al., 1999).

The empirical work on reading difficulty subtypes deriving from the simple-view on reading model has typically employed cut-off scores of word recognition and reading comprehension (Catts et al., 2003; Leach et al., 2003; Nation et al., 2004; Shankweiler et al., 1999). Because word recognition skills and reading comprehension correlate highly particularly in the 
early school years in the context of English language (e.g. Catts et al., 2003; Shankweiler et al., 1999), the stability and generality of the reading difficulty subtypes suggested thus far is not clear or evident. In two recent reading type classifications on random samples of Finnish $2^{\text {nd }}$ graders only three reading subtypes were identified (Lerkkanen, Rasku-Puttonen, Aunola, \& Nurmi, 2004; Poskiparta, Niemi, Lepola, Ahtola, \& Laine, 2003): one with reading comprehension difficulties, second with both word recognition and reading comprehension difficulties, and third with no reading difficulties. In contrast to previous studies these data did not support a reading subtype with only word recognition difficulties. This finding may, however, be due to the close link of word recognition and reading comprehension after only two years of formal school instruction, to sample size, or statistical power issues regarding the traditional cluster analysis they employed.

In the present study we aim to overcome some of the limitations of earlier studies in the identification of reading difficulty subtypes. First, small sample sizes have been an issue in many of the previous studies. In this study, we examine the development of word recognition and reading comprehension in a large sample $(\mathrm{n}=1750)$ of Finnish $1^{\text {st }}$ and $2^{\text {nd }}$ graders including a total of 93 school classes. Second, most of the previous reading subtype classifications have been based on single time points and only occasionally longitudinal follow-up of the reading subtype stability has been carried out (e.g. Catts et al., 2004; Lerkkanen et al., 2004). In this study we identify children based on the analysis on the heterogeneity in their developmental paths in word recognition and reading comprehension during the first two grades and across several time of measurement. Third, the effect of classroom membership has not previously been controlled in the studies identifying reading difficulty subtypes although its effect on children's learning has been shown to be relevant (McCoach et al., 2006; Rowan et al., 2002). Because our data comprise of whole classrooms, we were able to assess the classroom effect in the design. Fourth, we were able to avoid the limitations of the traditional, most typically cut-off score based reading type analysis by employing a more advanced method of sub-group identification (Mixture modeling, Muthen, 2001) 
than previously. The advantages of Mixture modeling over the use of cut-off criterions, traditional cluster analysis, and ISOA analysis (used in Lerkkanen et al., 2004, see Bergman \& El-Khouri, 1999) are that it allows one to isolate measurement error, to base the sub-grouping on several measurements instead of relying on one measurement occasion, and it provides statistical tests for selection of the best solution. Mixture modelling, thus, gives us a much more powerful tool to estimate whether different reading profiles really exist in the present data. In addition, the explicit inclusion of children with high familial risk for dyslexia rises the probability of identifying children with word recognition.

The second aim of the present study is to examine differences in early development and reading experiences of the children following the different reading trajectories (i.e., belonging to the different reading subtypes). These analyses are based on the detailed longitudinal information on the early (starting from age 1 years) language and literacy development and reading experiences that is available for the 200 children with and without familial risk for dyslexia (included within the total sample of 1750 children) who have been followed up since birth in the JLD study. Some earlier reading difficulty subtyping studies have included language and literacy predictors from Kindergarten or from earlier school grades (Catts et al., 2003, Leach et al., 2003; Poskiparta et al., 2003), but there is a lack of studies describing the early language development of the children with differing reading development subtype. In particular, little is known about the early developmental paths leading to poor comprehension (Nation et al., 2004).

Both the studies attempting to identify reading difficulty subtypes and the studies focusing on predictors of continuous reading outcomes, suggest that the early risk factors for difficulties in word identification and/or reading comprehension difficulties are partly different (e.g. Bishop \& Snowling, 2004; Catts, Adlof, Hogan, \& Weismer, 2005; Catts et al., 2003; Leach et al., 2003; Muter, Hulme, Snowling, \& Stevenson, 2004; Nation \& Nordbury, 2005; Oakhill, Cain, \& Bryant, 2003; Phillips \& Lonigan, 2005; Tunmer \& Hoover, 1992). The best proximal predictors of 
future word recognition skills have been repeatedly shown to be letter knowledge and phonological awareness (e.g. Adams 1990; Byrne, 1998; Elbro, Borstrøm, \& Petersen, 1998; Gallagher, Frith, \& Snowling, 2000; Lonigan, Burgess, \& Anthony, 2000; Pennington \& Lefly, 2001; Scarborough, 2001; Snow, Burns, \& Griffin, 1998; Vellutino, Fletcher, Snowling, \& Scanlon, 2004). In addition, especially in consistent orthographies such as Finnish or German, high predictive associations have been observed also between word reading and naming speed (e.g. Holopainen, et al., 2001; Wimmer, Mayringer, \& Landerl, 1998, 2000; Wimmer \& Mayringer, 2002). This close association between rapid naming and reading skill in these languages can be understood through the transparency of the writing system. In Finnish for example, the writing system consists of only of 24 grapheme-phoneme combinations and every word can be read relying on the phonological strategy which together make achieving accuracy in basic reading a relatively easy and a very fast process for beginning readers (e.g. Seymour, Aro, \& Erskine, 2003). The highly transparent orthography is not to the same extent an asset in acquisition of fluent reading, and reading difficulties are typically identified by employing fluency measures.

Individuals with poor comprehension skills (in absence of word recognition difficulties) do not typically have difficulties with phonological awareness tasks but they perform below average in a wide range of other oral language measures especially in tasks tapping vocabulary, listening comprehension, semantics, and morphosyntax (e.g. Cain, Oakhill, \& Bryant, 2004; Nation et al., 2004; Roth, Speece \& Cooper, 2002; Stothard \& Hulme, 1995; Senechal \& LeFevre, 2002; Storch \& Whitehurst, 2002). Poor comprehension has often been associated with problems in 'higher level skills', e.g. with deficits in short term memory, poor inference making, and comprehension monitoring (e.g. Cain et al., 2004). Some poor comprehenders also perform below average in general cognitive ability (Nation et al., 2004).

Of the oral language skills, the awareness of inflectional morphology is highly relevant in the Finnish language in which single word may have thousands of variants through 
inflections (Karlsson, 1999). Many of these variations are differentiated not only in the ending but also in the stem of the words by single phonemes (e.g. koti [home]; kodissa [at home]; kodista [from home]). Morphological skills are associated with reading development in Finnish as documented by data from the JLD (Lyytinen, Aro, Holopainen et al., 2005). In agglutinative languages such as ours words tend to be relatively long and, thus, intact verbal short term memory can also be expected to have an important role in fluent reading and comprehension of Finnish.

A division between phonological and 'nonphonological' language skills is far from clear-cut but may provide a heuristic tool for theoretical and empirical analysis. Although language problems of children with word recognition difficulties are thought to predominantly reside within the phonological language domain, variation in word recognition has been found to be predicted also by oral language abilities not commonly included into phonological domain such as vocabulary knowledge (e.g. Catts, Fey, Zhang, \& Tomblin 1999; Nation \& Snowling, 2004). This suggestion is supported also by the findings of the prospective follow-up studies of children with familial risk for dyslexia. In addition to the most obvious measure, phonological awareness, children at risk for dyslexia have been found to perform on average at a lower level than control children in letter knowledge, and rapid serial naming, but also in tasks measuring vocabulary (e.g. Elbro et al., 1998; Gallagher et al., 2000, Lyytinen et al., 2004; Lyytinen et al., 2006; Scarborough, 1990; Snowling, Gallagher \& Frith, 2003). Catts et al (2003) has reported that poor comprehenders performed as poorly as children with word recognition difficulties in phonological awareness and rapid naming. This finding may, however, be explained by poor comprehenders' difficulties in understanding task demands (Nation, 1999).

Previously, we (Lyytinen et al., 2006) have examined the heterogeneous trajectories of the JLD children's language and literacy skills and their association with early reading and spelling ability. The results suggested that there are at least three routes to difficulties in reading acquisition; the most explicit routes are characterized by problems in phonological awareness, naming speed or 
letter knowledge. In the analyses of Lyytinen et al., the outcome reading was a composite of fluent word recognition and spelling measures and the focus was on heterogeneous paths of early language and literacy development. In the present analyses, however, we focus on heterogeneous reading trajectories in word recognition and reading comprehension and examine retrospectively the early language and literacy development. We included here the early developmental paths in same seven skill domains of early language and literacy development as Lyytinen et al did, that is: 1) receptive and 2) expressive language skills, 3) inflectional morphology skills, 4) memory, 5) retrieving words efficiently from memory (naming speed), 6) letter knowledge and 7) phonological awareness skills since they all are relevant potential early predictors of reading skill as described above. Furthermore, we examine the effects of familial risk for dyslexia and the amount of reading experiences on variation in reading development. The amount of reading experiences have been found previously to be higher among children with better reading skills (e.g. Leach et al., 2003; Leppänen, Aunola, \& Nurmi, 2005; Scarborough, Dobrich, \& Hager, 1991; Senechal \& Lefevre, 2002).

More specifically, we ask: (1) can heterogeneous developmental paths of reading development be identified through reading typing (using mixture modeling) based on profiles of 1st through 2nd grade word recognition and reading comprehension skills in a longitudinal sample of children with familial risk for dyslexia, their controls and classmates? (2) What kind of early language and cognitive skill profiles and reading experiences characterize children in the JLD follow-up with differing reading development?

Based on the evidence on the divergence of word recognition and reading comprehension skill in children already after few years of formal school attendance (e.g., Catts et al., 2003; Leach et al., 2003; Lerkkanen et al., 2004; Nation et al., 2004, Poskiparta et al., 2003; Shankweiler et al., 1999) we expected to find groups of children with differing developmental paths during the first two school years. Children with familial risk for dyslexia were expected be over- 
represented among children with reading problems (Elbro et al., 1998; Finucci, Guthrie, Childs, Abbey, \& Childs, 1976; Gilger, Pennigton, \& DeFries, 1991; Hallgren, 1950; Lyytinen et al., 2004; Olson, Datta, Gayan, \& DeFries, 1999; Pennigton \& Lefly, 2001; Scarborough, 1990). By definition, children at risk for dyslexia have a high propensity for difficulties particularly in word recognition, but difficulties in decoding skill may be reflected also in reading comprehension especially during the early school years. Difficulties in word recognition were expected to be related in particular with slow early development of phonological awareness, letter knowledge, and rapid naming. Reading comprehension difficulties, on the other hand, were expected to be related with slow early development particularly in vocabulary, morphological awareness, verbal IQ, and short term memory (Cain et al., 2004; Nation et al., 2004; Nation et al., 2002). And, finally, the amount of reading practice was expected to be higher among proficient readers than children with any type of reading difficulties (Leach et al., 2003; Senechal \& LeFevre, 2002). 


\section{Method}

\section{Participants}

Data for this study were drawn from the Jyväskylä Longitudinal Study of Dyslexia (JLD), a prospective follow up of children from birth to school age. The JLD seeks to identify early language development and precursors of dyslexia (for the most recent review of results, see Lyytinen, et al., 2004). From four successive age cohorts of families invited for screening, a total of 214 families from the city of Jyväskylä and its surrounding communities in the Province of Central Finland joined the study prior to the birth of their children. Half of the participating families include a parent who has been diagnosed with dyslexia and who reports similar problems among immediate relatives. The children from these families are referred to as the at-risk group. The control group comprises children from families whose parents gave no personal or familial report of reading or spelling difficulties. Parents also underwent extensive cognitive and literacy-based assessment (see Leinonen, et al., 2001 for full details). In terms of distribution, the level of parental education is representative of the Finnish population and did not differentiate the at-risk and control groups. All the children are native Finnish speakers and have no mental, physical, or sensory difficulties. At the present stage of the JLD study, whereby the youngest of the four cohorts is now at $3^{\text {rd }}$ grade in school, attrition rate is low with 199 of 214 families continuing to participate in the project.

When the JLD children entered school (at the year they turned 7 years), group assessments of the first two of four age cohorts were conducted in schools for the whole classes. The third and fourth age cohorts were assessed individually. The data from classmates and the JLD children in the present data comprises 1756 children from 93 classes who participated in to the group tests at least twice. Among the classmates' data, there was missing data because we followed the JLD child through $1^{\text {st }}$ and $2^{\text {nd }}$ grade and we did not control for presence of all other children at the group assessment day. There were also some school and class changes that caused us to miss longitudinal 
data from all time points for some classmates of the JLD -children. The outliers of the individual data were relocated to the tails of distributions.

\section{Measures}

\section{Reading}

Fluent word recognition was assessed as a part of group tests held two times at $1^{\text {st }}$ grade (November and April) and two times in $2^{\text {nd }}$ grade (November and April). Reading comprehension was assessed as a part of group tests held once in $1^{\text {st }}$ grade (April) and two times in $2^{\text {nd }}$ grade (November and April). Tester was either a trained university student or teacher from the school. Detailed information and consultation was provided for the teachers. Reading skills were assessed for most of the cases during normal school lessons. All test scorings were done in the university and teachers received the test results for the children of their own class.

Fluent word recognition: In fluent word recognition test child's task was to connect a picture with a correct word. The test consisted of 80 pictures and four words attached to each picture in the test. In the $1^{\text {st }}$ grade children had 5 minutes and in the $2^{\text {nd }}$ grade 2 minutes to complete the task. Items were identical at time points 1 and 4, and at time points 2 and 3. This task is a part of nationally normed test pattery, Allu (Lindeman, 2000).

Reading comprehension: A sentence comprehension task was used at $1^{\text {st }}$ grade on April (Lerkkanen, Poikkeus, \& Ketonen, in press). In this task child was presented two pictured fictional stories. Both stories had six pictures accompanied by four sentences which described the situation in each picture. Into one of the describing sentences a word that did not fit to the content of the story line depicted in the picture was added. Child's task was to identify this unsuitable wrong word. Two points were granted of each correctly identified wrong word child spotted and one points if the child had marked several words from the correct sentence in addition to the exact wrong word. There was a time limit of 10 minutes to complete the task. 
from identification of the sentence where the mistake was (even though not the exact erroneous word was not identified).

Text comprehension tasks were used at the $2^{\text {nd }}$ grade assessments. The task used is a part of national test pattery, Allu (Lindeman, 2000). In this task children got a short text to read and were asked to answer to 12 questions. At the fall of $2^{\text {nd }}$ grade the text was a non-fictional description about judo (146 words in length). There were 11 questions with alternative choices and one where the child was asked to arrange seven statements into a consecutive order based on the information gathered from the text. At the spring of $2^{\text {nd }}$ grade the text was a non-fictional description about gymnastic exercise (114 words in length). There were 11 questions with alternative choices and one where the child was asked to arrange five statements into a consecutive order based on the information gathered from the text. One point was granted from each correct answer, resulting a maximum of 12 points. Children had unlimited time to complete the task.

\section{Early Skill Measures}

Theoretical basis underpinned the selection of the seven core skill domains and age points of interest and the identification of the key measures in each skill area evolved from empirical analysis of the data. To ensure high reliability of the measures, composite means of separate measures were formed where possible. Table 1 details the seven developmental skill domains, assessment ages, standardized alpha produced for composite scores and tasks included in the analysis. Receptive language was assessed on 6 occasions between the ages of 12 months and 5 years. Early language tasks adapted from the MacArthur Communicative Development Inventory (CDI; Fenson, et al., 1994 (see Table 1) for the Finnish language (Lyytinen, P., 1999) relied upon structured parental report using checklists whereby parents noted the total number of words comprehended by their child. Measures of Expressive language were derived on 7 occasions between 12 months and 5.5 years of age, again with the earlier measures involving parental checklist report of vocabulary 
production and maximum sentence length (mean number of morphemes uttered, for details of the the assessment of vocabulary and inflectional skills using CDI, see Lyytinen \& Lyytinen, 2004). Morphological knowledge, including the ability to inflect adjectives, nouns and verbs was assessed 2 times at 3.5 and 5.5 years. The assessment of Memory relied upon traditional paradigms involving digits but was also expanded to include syllables, nonwords and sentence-length items in the recall. Memory was assessed between the ages of 3.5 and 6.5 years on 4 occasions. Traditional paradigms (Denckla \& Rudel, 1974, 1976) for Rapid serial naming were also used, including letters, objects, numbers and colors. Mixed stimulus paradigms were not included although the matrix size was increased in accordance with age. Three blocks of rapid naming assessments took place between the ages of 3.5 and 6.5 years. Letter knowledge and associated letter recognition tasks were implemented on 5 occasions between the ages of 3.5 and 6.5 years. An extensive battery of tests of Phonological awareness was implemented between the ages of 3.5 years and 6.5 years (for more details, see Puolakanaho et al., 2003). Tasks involved the manipulation and production of subword level units (syllables and phonemes). At the ages of 5 years and 8 years, Verbal and Performance intelligence quotients were also obtained with a short-form administration of the Wechsler PreSchool and Primary Scales of Intelligence (WPPSI-R; Wechsler, 1989).

Insert Table 1 about here.

The composites for each domain were formed by calculating a grand mean of scores. The battery of tests included computerized tests (Cognitive Workshop, Universities of Dundee and Jyväskylä; see Erskine \& Seymour, in press for extensive implementation), tests with national norms (Lindeman, 2000) and specially designed group tests (Nevala \& Lyytinen, 2001). The assessments (type and time point) are detailed in Table 1.

\section{Reading Experience}

When the children were 2, 4, 5, 6, 7, and 8 years old, parents completed a Reading Models Questionnaire, whereby the amount of reading experiences a child had received was estimated. 
Shared reading. To form a composite score of shared reading we employed parental reports both on the frequency and on the amount of time of the children's reading activities in the home. At age 2 years, the shared reading measure consisted of a mean composite score of four items; 1) mother reads to the child, 2) father reads to the child, 3) amount of picture book reading, and 4) the typical duration of reading episode when the child is reading with an adult. Parents responded to the first three items using a four-point scale $(1=$ not at all/seldom, $\ldots, 4=$ daily $)$, and to the fourth with a three-point scale $(1=$ less than $5 \mathrm{~min} /$ day, $\ldots, 3=$ longer than 15 min/day). A mean composite score of the following four items covered shared reading at ages 4, 5, 6, 7, and 8 years: 1) mother reads to the child, 2) father reads to the child, 3) the typical duration of reading episode when the child is reading with an adult, and 4) the total amount of time in a day the child spends reading a book with an adult. Parents responded to the first two items using a five-point scale $(1=$ not at all/seldom, $\ldots, 5=$ several times a day $)$ and to the third and fourth items using a three-point Likert scale $(1=$ less than 15 min/day, .., 3 = longer than $45 \mathrm{~min} /$ day).

Reading alone. The amount of children's solitary reading activities was calculated from three questions at ages $4,5,6,7$, and 8 years: 1) how often child reads alone, 2) the typical duration of reading episode when the child is reading alone, and 3) the total amount of time in a day the child spends reading a book alone. Parents responded to the first item using a five-point scale (1 $=$ not at all/seldom, $\ldots, 5=$ several times a day) and to the second and third items using a threepoint Likert scale $(1=$ less than $15 \mathrm{~min} /$ day, $\ldots, 3=$ longer than $45 \mathrm{~min} /$ day $)$. 


\section{Results}

Table 2 presents the correlation coefficients, descriptive statistics, and intraclass correlations of fluent word recognition and reading comprehension at each time point. As shown by Table 2, the mean performance in fluent word recognition (amount of words decoded per minute) increased rapidly during the one year time between assessments waves at $\mathrm{T} 1$ and $\mathrm{T} 2$ but not so much between the last two assessments on the $2^{\text {nd }}$ grade. The stability of fluent word recognition was very high already from the first measurement occasion onwards but the stability of reading comprehension was not as high as shown by correlations in Table 2. Fluent word recognition was closely linked with reading comprehension, and its correlations with reading comprehension were similar to those among reading comprehension measures across time. Note that the reading comprehension measure at $\mathrm{T} 2$ was not yet based on text reading as at $\mathrm{T} 3$ and $\mathrm{T} 4$ because it was considered too difficult for many children and a pictured sentence comprehension test was used instead.

Since the measures of reading comprehension and fluent word recognition were based on group assessments within school classes, intraclass correlations were calculated. The intraclass correlations (see Table 2) indicated that there was indeed a significant classroom membership effect. Of the variance in fluent word recognition performance $5 \%-10 \%$ was shared by classroom members and the rest was due to individual differences. In the reading comprehension classroom effects were between $4 \%$ and $6 \%$. Therefore, in the subsequent analyses, we used the COMPLEX -option provided by M-plus program, which takes into account the hierarchical nature of the sample.

Insert Table 2 about here

The present data sample included three subsamples; the JLD follow-up at-risk and control children, and their classmates. Table 3 provides the means, standard deviations, sample sizes, and group comparison results of the subsamples. On average, the JLD at-risk children were 
performing on a lower level in fluent word recognition tasks than the JLD control children or classmates. JLD control children outperformed the JLD at-risk children and the classmates at the $1^{\text {st }}$ grade, but at the $2^{\text {nd }}$ grade assessments they performed on average at the same level as classmates in fluent word recognition task. In reading comprehension the at-risk children were performing on a lower level than control children and classmates at the end of $1^{\text {st }}$ grade, but had reached classmates' level at the fall of $2^{\text {nd }}$ grade and control children's level at the spring of $2^{\text {nd }}$ grade. Classmates reached the level of control children at the spring of $2^{\text {nd }}$ grade.

Insert Table 3 about here

\section{Examination of Heterogeneity in Reading Development: Mixture Modeling}

Next, we examined the heterogeneity in children's developmental profiles of fluent word recognition and reading comprehension. For this purpose, we utilized the mixture modeling feature of the MPLUS (version 3) program (Muthén \& Muthen, 1998-2003). Mixture modeling identifies mixtures of subpopulations (latent classes) from observed data and provides statistical tests to aid in the evaluation of the existence and amount of the subpopulations.

The mixture procedure of the present analyses was based on a model with two latent factors; one for reading comprehension and the other for fluent word reading (see Figure 1). This model fitted the data very well $\left(\chi^{2}(11)=23.37, \mathrm{p}=.02, \mathrm{CFI}=1, \mathrm{TLI}=1, \mathrm{RMSEA}=.025, \mathrm{SRMR}=\right.$ .012). In construction of the model, we searched first latent classes with distinct mean values of the two latent factors of fluent word recognition and reading comprehension. Because of the developmental nature of the present data, this approach was not able to provide a detailed picture of the data across age. Therefore, we moved on to modeling the mean structure in the level of the trajectories across age using the information from each time point. The factor means were fixed to be zero and the intercepts were estimated freely in each latent class. The model was estimated using the MLR estimation method. 
In the mixture modelling procedure we fitted models with different numbers of latent classes. To evaluate the appropriate number of latent classes we used three criteria: (a) the fit of the model was evaluated by three criteria: AIC (Akaike's information criteria), aBIC (Adjusted Bayesian Information Criteria) and Vuong-Lo-Mendel-Rubin test. The lower AIC and aBIC values indicate a better model and significant Vuong-Lo-Mendel-Rubin test results indicate a higher number of groups, (b) mean probabilities and number of children to be situated into a latent class, and (c) the usefulness and interpretativeness of the latent classes in practice. The five-class solution was confirmed as the best according to all these criteria (see Table 4 for indices for mixture models with differing numbers of latent classes).

\section{Insert Table 4 about here}

Table 5 and Figure 2 present the descriptive statistics of the final mixture solution of five latent classes. Note that we refer to these latent classes as reading subtypes hereafter to avoid confusion with school classes. The first reading subtype, referred to as 'Good readers' comprised $192(11.0 \%)$ children and their performance in all reading assessments was on a very high level. The second reading subtype, referred to as 'Average readers' was the largest group and comprised of $722(41.3 \%)$ children with average level reading skills. The third reading subtype, referred as 'Slow readers' comprised 435 (24.9\%) children whose reading development was characterized by somewhat below average level performance in fluent word recognition tasks but faster than average growth in reading comprehension. The fourth reading subtype, referred to as 'Poor comprehenders' comprised $173(9.9 \%)$ children with average performance in fluent word recognition tasks but slower than average growth in reading comprehension performance. The last reading subtype, referred as 'Poor readers' comprised 228 (13.0\%) children with poor performance in all reading assessments. Note that the values of reading skills have been standardized according to the classmates' distribution (classmates' mean $=0$ and standard deviation $=1$ ) in order to transform the variable scales to be identical. Therefore, the profile changes in Figure 2, such as those of reading 
comprehension in 'Slow readers' and 'Poor comprehenders', are not absolute but relational to other children's skill level at each time point.

The mean comparisons between the reading subtypes showed (see Table 5) that they were distinct in most time points and in both reading measures except for two occasions: 'Poor comprehenders' who performing in fluent word recognition as well as 'Average readers' in the $2^{\text {nd }}$ grade assessments and the 'Slow readers' and the 'Poor comprehenders' were as good in the reading comprehension task at the $\mathrm{T} 3$ assessment on fall of $2^{\text {nd }}$ grade. Note that the amount of children within each reading subtype vary from time point to time point, depending on the amount of missing values.

Insert Figure 2 about here

Insert Table 5 about here

\section{Early Developmental Paths and Characteristics of the Reading Subtypes}

Next, we examined what early characteristics or skills may differentiate the reading subtypes that were identified above. For this purpose we had data available of 191 children. Of the 1750 children on whose data the reading typing solution was based, 104 were children with familial risk for dyslexia and 87 were control children participating in our comprehensive follow-up study (JLD).

\section{Reading Subtypes and Familial Risk for Dyslexia}

Table 6 presents the frequencies of the five reading subtypes for each study group. The chi-square test statistics showed group differences $\left(\chi^{2}(8)=22.44, p=.004\right)$. Analysis of residuals revealed that the at-risk children were over-represented in the 'Slow readers' (adjusted residual $=2.5$ ) whereas their amount was lower than expected among 'Average readers' (adjusted residual $=-2.0$ ). For the control group children, on the other hand, the membership of the 'Good readers' subtype was more common than expected (adjusted residual $=3.0$ ) and membership of the 'Slow readers' subtype was rarer than expected (adjusted residual $=-1.9$ ). The amount of children with some sort of reading 
difficulties ('Slow readers', 'Poor comprehenders', and 'Poor readers') was overall higher among the JLD at-risk children (58.7 \%) than among JLD controls (36.8 \%) or among classmates (47.4\%).

Insert Table 6 about here

\section{Reading Subtypes and Early Language and Literacy Development}

Figure 3 shows the before school-age developmental profiles of the five reading subtypes in the seven domains of language and literacy skills; receptive and expressive vocabulary, morphological awareness, phonological awareness, letter knowledge, short term memory, and rapid naming.

Overall the profile comparisons showed that the children of the 'Good readers' subtype showed highest performance in all early tasks we included, beginning from the 2 -year olds' vocabulary. The performance of the 'Average readers' was close to that of the 'Good readers'. 'Good readers' performed significantly better (pairwise comparisons with Bonferroni correction) than the 'Average readers' in letter knowledge after age 4.5 years, in phonological awareness after age 5.6 years, and in verbal IQ at age 8 . The performance of the 'Poor readers' was poorest in all early tasks, and the difference from the 'Average readers' and 'Good readers' reached significant level everywhere but in receptive and expressive language at 1 year olds' assessments. Furthermore, phonological awareness, RAN, and letter knowledge at age 6.5 years differentiated 'Poor readers' from all the other reading subtypes. 'Slow readers' scored also below the competent readers ('Average' and 'Good' readers) in phonological awareness, letter knowledge, and RAN at all time points, and in vocabulary measures, morphological awareness, and verbal short term memory after age 5 years, and in verbal IQ at age 8 years. Their performance in RAN at age 6.5 years differentiated 'Slow readers' from all the other reading types but 'Poor readers'. The performance IQ at age 8 was on average at a lower level among 'Slow readers that' 'Good readers'. 'Poor comprehenders', on the other hand, were performing below the 'Good readers' after age 5 years in receptive vocabulary, phonological awareness, and in vebal short term memory. Furthermore, expressive vocabulary at ages 3.5 and 5.5 years, all letter knowledge assessments, and verbal IQ at 
age 8 differentiated 'Poor comprehenders' from 'Good readers'. A particular drop in 'Poor comprehenders' early skill profile was seen in the expressive vocabulary development.

Insert Figure 3 about here

\section{Reading Types and Amount of Reading Experiences}

Figure 4 illustrates the across age profiles of the amount of reading experience either alone or with parent in the five reading types. Before school age, the children with low level of both fluent word recognition and reading comprehension ('Poor readers') were found to have had significantly less shared reading experiences with parents than children of 'Average readers' and 'Good readers' reading types (pairwise comparisons with Bonferroni correction). After school entry, however, there were no significant mean differences in shared reading experiences between the reading types.

The amount of reading alone did not differentiate the reading types at ages 4 and 5 but at age 6 years the 'Poor comprehenders' and 'Poor readers' were reading less than children of 'Good readers'. At age 7 the 'Good readers' were using more time on average reading alone than children of any other reading type At age 8 there was still a significant difference between 'Good readers' and 'Poor readers'. The amounts of reading alone or with parent were not different in the at-risk and control children in any of the time points. Parental education levels did not differentiate the reading types.

Insert Figure 4 about here 


\section{Discussion}

This study aimed to substantiate the claims based on the simple view of reading that even though word recognition and reading comprehension are strongly related skills distinct subtypes of reading difficulties with discrepancy in word recognition and comprehension performance can be identified (e.g., Catts et al., 2003; Leach et al., 2003; Lerkkanen et al., 2004; Nation et al., 2004, Poskiparta et al., 2003; Shankweiler et al., 1999). This study adds to previous findings by conducting analyses in a large data set $(\mathrm{n}=1750)$ within a context of a consistent language (Finnish), by including classrooms $(n=93)$ of students with the whole range of variation in reading skills, by controlling for the effects of classroom membership, and by using several time-points for identification of the reading subtypes. We also analysed the early language and literacy development, reading experience, and the status concerning familial dyslexia risk of the children belonging to the reading types within the JLD follow-up sample (104 children at risk, and 87 control group children). Using advanced mixture modelling procedure we were able to verify that varying reading subtypes, five altogether, that emerged in our data are truly distinct. These reading subtypes fit nicely the predictions that can be induced from the simple view of reading (Gough \& Tunmer, 1986; Tunmer \& Hoover, 1992). Employing multiple time points allowed us to identify two particularly interesting subtypes: one for which reading comprehension development begins to lag behind peers by time, and another for which reading comprehension skills begin to approach the average level. The five reading subtypes differed with respect to early language and literacy development, amount of reading experience, and familial risk status which further strengthens the validity of the classification.

Instead of four different reading subtypes predicted from simple view of reading and the specified in some of the previous studies (e.g., Catts et al., 2003; Leach et al., 2003; Nation et al., 2004; Shankweiler et al., 1999), the mixture analysis of the present study identified five reading types; (1) 'Poor readers' who had poor skills in both word recognition and reading comprehension, 
(2) 'Slow readers', who had below average fluent word recognition performance combined with fast growth in reading comprehension, (3) 'Poor comprehenders' who had average word recognition combined with slower than average reading comprehension development, (4) 'Average readers' who had average skills in both word recognition and reading comprehension, and (5) 'Good readers' who had high level of performance in both reading skills. The findings of the five distinct reading subtypes showed that even though word recognition and reading comprehension were highly correlated ( $\mathrm{r}=.81$ between across-age latent factors), children with a discrepancy in the reading skills can be identified in our data. The close association of word recognition and reading comprehension was expected (e.g. Shankweiler et al., 1999) and for most of the children reading skills did go together. The members of the reading subtypes of 'Poor readers', 'Average readers', and 'Good readers' who showed no discrepancy in their performance of word reading and reading comprehension comprised $63.9 \%$ of children in our data. The 'Slow readers' and 'Poor comprehenders', on the other hand, showed a developmental pattern whereby their word reading level and reading comprehension separated in time and showed a discrepancy already at the end of second grade. The developmental pattern of the 'Slow readers' reflects also in a way the close association of fluent word recognition and reading comprehension in that their reading comprehension appears to have begun to develop rapidly after the word recognition reached necessary level for text comprehension.

The comparison between the findings of previous studies that have identified reading subtypes is difficult because of the variability in measures, classification strategies, and ages of the children. Our finding of five reading subtypes does not contradict the previous classifications of four reading types, since lack of differentiation between high and average level readers in previous studies has not been in the focus of previous studies that have searched subtypes among children with reading difficulties (e.g., Catts et al., 2003; Leach et al., 2003; Nation et al., 2004; Shankweiler et al., 1999) whereas our sample included the whole variation in reading skills. In comparisons of 
the present reading subtypes to previous studies, e.g., Catts et al., (2003), Leach et al., (2003), Nation et al., (2004), and Shankweiler et al., (1999) at least the following additional differences need to be taken into account: our subtype identification was based on several time points (vs. a single time point), and secondly, the word recognition test we used was a speeded test tapping fluency along with accuracy. Use of a speeded measure was a natural choice in the Finnish language context because reading difficulties are manifested in speed of reading in consistent languages (e.g. Aro \& Wimmer, 2003; Porpodas, 1999). To underline this point, we used the label 'Slow readers' to refer to the subtype with less than average fluent word recognition combined with good reading comprehension.

In two recent Finnish studies from another data set but with same age children, only three reading subtypes were identified (Lerkkanen et al., 2004; Poskiparta et al., 2003). These studies did not obtain two of the present subtypes, one with only word recognition difficulties ('Slow readers') and another with high reading skills ('Good readers') perhaps due to their smaller sample sizes, problems of statistical power of the traditional cluster analysis, and different set of variables. Poskiparta et al. (2003) based their cluster analysis on measures of both reading skills and spelling and they explicitly looked for three clusters of children and did not report whether any other solutions were explored. Lerkkanen et al. (2004) used a longitudinal clustering analysis approach (ISOA analysis) with two reading comprehension measures and one word recognition measure in a small sample of 90 children. As they speculated themselves, because of their small sample the amount of poor readers was so small that the division of different poor reading subtypes was not possible.

The above mentioned factors related to differences in samples and method of subtyping naturally affect also to the comparisons of proportions of children within the different reading types between the studies. To be able to provide some comparisons to previous studies we interpreted the 'Poor readers', 'Slow readers' and 'Poor comprehenders' subtypes of the present study to 
correspond roughly to the samples of children with reading difficulties used in previous studies (e.g., Catts et al., 2003; Leach et al., 2003; Nation et al., 2004; Shankweiler et al., 1999). Among the three reading subtypes with any reading difficulties of the present study, $52 \%$ of the children showed the 'Slow readers' reading pattern characterized by slow word recognition but fast growth in reading comprehension. This corresponds well with the finding of Leach et al. (2003) who reported that $49 \%$ of their similar age poor readers had word recognition difficulties without reading comprehension difficulties. Catts et al. (2003), however, reported that $35.5 \%$ and Shankweiler et al. (1999) reported that only $18 \%$ of their samples of poor readers showed this pattern of only word recognition difficulties. The amount of Poor readers (both word recognition and reading comprehension difficulties) has varied, on the other hand, between $35.7 \%$ of the poor readers (Catts et al., 2003) and $72 \%$ of the poor readers (Shankweiler et al., 1999). In the present study, $27 \%$ of the children with reading difficulties were having both word recognition and reading comprehension difficulties whereas Poor comprehenders comprised $21 \%$ of the poor readers. The amount of Poor comprehenders in previous studies conducted among poor reader's samples has been 6 - 15 \% (Catts et al., 2003; Leach et al., 2003; Shankweiler et al., 1999). Nation et al., (2004), however, suggested that the amount of poor readers is about $10 \%$ of all children, which corresponds well with the findings of the present study $(9.9 \%$ were classified as Poor comprehenders).

The identification of the separate reading types raised question of their origin. What differentiates these groups of children from each other? Because we controlled for the effect of class membership in the Mixture analyses, the variance coming from differences in the quality of reading environment at school could not be the answer. The focus of the present study was not to further examine the determinants of classroom membership effect. Based on the present analyses we can however conclude that even in Finnish schooling system where almost $100 \%$ of the children participate in public schools with a national curriculum and a reading instruction that 
emphasizes systematic use of phonics and the main focus is on the letter sound relations, this source of variability was not very strong although statistically significant; $4 \%-6 \%$ for reading comprehension and 5\%-10\% for fluent word recognition depending on the assessment time point.

The comparisons of the reading subtypes was proceeded with the analyses within our JLD follow-up participants (in this study $n=191$ ) from whom we have a detailed data of their risk status for dyslexia (based on presence of dyslexia in the family), their early language and literacy development and amount of reading experience. In the comparison of the JLD children and their classmates, we found that the JLD control children showed significantly higher than average reading skills on the first grade, but this early advantage faded in the second grade. This early advantage may be in part associated with the participation in the intensive follow-up study but also to the fact that the JLD control children were selected as controls based on the normal reading level of their parents and absence of reading difficulties in close relatives. Among the classmates, however, normal variation of risk for difficulties in reading or other kinds of difficulties exists.

The familial risk status for dyslexia was found to have a significant role in reading development. The children with familial risk for dyslexia performed on average at a lower level in reading than peers, as expected (Elbro et al., 1998; Finucci, Guthrie, Childs, Abbey, \& Childs, 1976; Gilger, Pennigton, \& DeFries, 1991; Hallgren, 1950; Lyytinen et al., 2004; Olson, Datta, Gayan, \& DeFries, 1999; Pennigton \& Lefly, 2001; Scarborough, 1990) and the at-risk children were over-represented in the reading subtypes with difficulties in fluent word recognition (Poor readers and Slow readers). This finding is in line with the expectation that the children at-risk for dyslexia would show inherited reading difficulties that fit to the definition of dyslexia which is based on word recognition/decoding and not on reading comprehension (Lyon, Shaywitz, \& Shaywitz, 2003).

Comparison of the early skill development showed that children with average or Good level reading profile had higher skill level in several early language and literacy tasks from age 2.5 
years onwards than children of the other three reading subtypes. The differences between subtypes were most evident in the tasks of phonological awareness, letter knowledge, rapid naming and expressive vocabulary. These differences increased in time and became clearly noticeable after age 5 years. The 'Poor readers' lagged behind other subtypes and 'Good readers' were outperforming other reading subtypes particularly in these tasks. These findings are compatible with the existing understanding of the origins of word recognition difficulties (Vellutino et al., 2004) and shows that the variation in these skills can separate children also at the higher end of the distribution.

The 'Slow readers' showed similar level of rapid naming performance as the 'Poor readers' which was expected since it is linked particularly with reading fluency (e.g. Holopainen, et al., 2001; Wimmer, Mayringer, \& Landerl, 1998, 2000; Wimmer \& Mayringer, 2002). The 'Slow readers' significantly outperformed the 'Poor readers' in phonological awareness, and letter knowledge at age 6.5. Also the expressive vocabulary, verbal short term memory and morphology of 'Slow readers' appeared to be at a higher level than those of the 'Poor readers' but these differences did not reach the level of significance in the paired comparisons. These strengths may support the 'Slow readers' reading development in that they performed on a somewhat higher level than 'Poor readers' in fluent word recognition task and were able to develop reading comprehension to average level.

The 'Poor comprehenders' showed no radical deficits in early language development even though they were performing somewhat below average in all the early skills. The mean performance of this group was at a significantly lower level that that of 'Average readers' and 'Good readers' in vocabulary skills, phonological awareness, short term memory, and letter knowledge after age 5. In fact, their early language and literacy development did not differ significantly anywhere from that of the 'Slow readers'. Catts et al (2003) reported similar findings concerning phonological awareness and rapid naming. Poor comprehenders' difficulties in understanding task demands have been suggested to explain these findings (Nation, 1999). The 
small size of this group makes difficult to obtain statistically significant differences but inspection of the early skill profiles show a trend that the development of expressive vocabulary was the most compromised early skill of the 'Poor comprehenders'. This trend is in line with previous findings of the predictors of reading comprehension (e.g. Nation et al., 2004; Roth, Speece \& Cooper, 2002; Stothard \& Hulme, 1995; Senechal \& LeFevre, 2002; Storch \& Whitehurst, 2002). Since reading comprehension is probably still a developing skill at the end of $2^{\text {nd }}$ grade all of the 'Poor comprehenders' may not be poor later on. A clearer pattern of compromised oral language and memory development may be true for children with poor comprehension still at later grades when the reading comprehension skill has stabilized. Inclusion of other early skills related to reading comprehensions, such as children's inference making skill or listening comprehension might have complemented the characterization of these children (e.g. Cain et al., 2004).

Unlike many previous studies we were able to examine the continuum of reading experience among children with differing reading types. The comparisons indicated that children with strongest reading skills were reading for fun more often than other children at school age whereas children with poorest reading skills were reading for fun less than other children at school age, as expected (e.g. Leach et al., 2003; Leppänen et al., 2005; Scarborough, Dobrich, \& Hager, 1991; Senechal \& Lefevre, 2002). At this early stage the reading skill differences are large and whereas the poorest readers are still working with basic decoding, some of the best readers may be reading short stories already at the first grade. Interestingly, the 'Poor readers' had had also significantly less shared reading experiences with parents before school age that 'Average readers' or 'Good readers'. The mechanism behind this association goes potentially through oral language development. The early shared reading experiences has been found to support children's oral language, particularly vocabulary development (e.g. Scarborough \& Dobrich, 1994; Sénéchal \& LeFevre, 2002), which, in turn, associates with better ability to comprehend text. It should be noted, however, that the direction of causality is not clear. In our previous analyses, for example, the large 
vocabulary at age 3.5 years predicted the amount of shared reading at subsequent years in the at-risk group whereas the amount of shared reading at age 2 years did not predict vocabulary at age 3.5 years (Torppa et al., submitted).

After school entry the amount of shared reading with parents increased among 'Poor readers' whereas it was slightly declining in other subtypes, particularly in 'Good readers'. Reason for this pattern may be that school entry awakes parents of the poor readers to see that their children need help with reading. At the same time, these children with poor reading skills were reading on average less alone than other children. It may be that their basic reading skills were not yet at a level that would make pleasure reading enjoyable or that their interest in reading is not as high as others. These differences in reading experiences have a potentially important role in all academic learning tasks that are based on written language since it can be suggested that if a child reads a lot she/he will develop further in reading fluency, learn efficient strategies of grabbing message from written text, and gain knowledge about wide range of topics.

Overall, the mixture analyses of the present study support the previous findings of heterogeneous reading development and shows that also in a highly transparent writing system a substantial heterogeneity is present already after only two years at school. The end on $2^{\text {nd }}$ grade is an interesting stage to assess reading comprehension because from that point on Finnish children face challenge of increased amount of text reading at school. Because of their slower than average reading comprehension development, the members of the 'Poor comprehenders' and 'Poor readers' subtypes can be expected to have difficulties in several school subjects. The fact that 'Poor readers' have difficulties in both fluent word recognition and in reading comprehension tasks is alarming because of the increasing amount of text reading needed in school subjects after completing the $2^{\text {nd }}$ grade. Even if their reading comprehension performance would depend on poor word recognition, which may eventually develop to a level needed for reading comprehension, there may not have enough time to keep up at the pace needed in ordinary school classroom teaching. Their lower level 
in several literacy and language skills and potential lack of interest in reading indicate that these children are in need of external support. In our Finnish sample it seemed to be provided at least by parents in form of increased level of shared reading. The problems of the 'Poor comprehenders' reading type are challenging also because their difficulties may easily fail to become noticed (e.g. Leach et al., 2003). 'Slow readers', on the other hand, were able to comprehend text even though their word recognition was not fluent if they were given enough time. The good comprehension ability is an important strength of these children. The increasing length and amount of reading materials after $2^{\text {nd }}$ grade may still be a stumbling stone for these children. On the other hand, these children may be those who are able to compensate their slow reading speed with other strengths, such as large vocabulary, good inference skills or wide knowledge base. 


\section{References}

Adams, M. J. (1990). Beginning to Read: Thinking and Learning about Print. Cambridge, MA: The MIT Press.

Aro, M. \& Wimmer, H. (2003). Learning to read: English in comparison to six more regular orthographies. Applied Psycholinguistics, 24, 621-635.

Bergman, L., \& El-Khouri, B. (1999). Studying individual patterns of development using I-states as objects analysis (ISOA). Biometrical Journal, 41, 753-770.

Bishop, D. V. M., \& Snowling, M. J. (2004). Developmental dyslexia and specific language impairment: Same or different? Psychological Bulletin, 130(6), 858-886.

Byrne, B. (1998). The Foundation of Literacy: The Children's Acquisition of the Alphabetic Principle. Hove, UK: Psychology Press.

Cain, K., Oakhill, J., \& Bryant, P. (2004). Children's reading comprehension ability: Concurrent prediction by working memory, verbal ability, and component skills. Journal of Educational Psychology, 96(1), 31-42.

Catts, H. W., Adlof, S. M., Hogan, T. P., \& Weismer, S. E. (2005). Are specific language impairment and dyslexia distinct disorders? Journal of Speech, Language, and Hearing Research, 48(6), 1378-1396.

Catts, H. W., Fey, M. E., Zhang, X., \& Tomblin, J. B. (1999). Language basis of reading and reading disabilities: Evidence from a longitudinal investigation. Scientific Studies of Reading, 3(4), 331-361.

Catts, H. W., Hogan, T. P., \& Fey, M. E. (2003). Subgrouping poor readers on the basis of individual differences in reading-related abilities. Journal of Learning Disabilities, $36(2), 151-164$.

Denckla, M. B., \& Rudel, R. G. (1974). Rapid "automatized" naming of pictured objects, colors, letters and numbers by normal children. Cortex, 10, 471-479. 
Denckla, M. B., \& Rudel, R. G. (1976). Rapid “automatized” naming (R.A.N.): Dyslexia differentiated from other learning disabilities. Neuropsychologia, 14, 471-479.

Dunn, L. M., \& Dunn, L. M. (1981). Peabody Picture Vocabulary Test-Revised. Circle Pines. MN: American Guidance Service.

Elbro, C., Borstrøm, I., \& Petersen, D. K. (1998). Predicting dyslexia from kindergarten: The importance of distinctness of phonological representations of lexical items. Reading Research Quarterly, 33, 36-60.

Erskine, J.M., \& Seymour, P.H.K. (in press). Proximal analysis of developmental dyslexia in adulthood: the cognitive mosaic model. Journal of Educational Psychology.

Fenson, L., Dale, P. S., Reznick, J. S., Bates, E., Thal, D., \& Pethick, S. J. (1994). Variability in early communicative development. Monographs of the Society for Research in Child Development, 59 (5, Serial No. 242).

Finucci, J. M., Guthrie, J. J., Childs, A. L., Abbey, H., \& Childs, B. (1976). The genetics of specific reading disability. Annual Review of Human Genetics, 40, 1-23.

Gallagher, A. Frith, U., \& Snowling, M. J. (2000). Precursors of literacy delay among children at genetic risk of dyslexia. Journal of Child Psychology and Psychiatry, 41, 203-213.

Gathercole, S. E., \& Adams, A-M. (1994). Children's phonological working memory: Contributions of long-term knowledge and rehearsal. Journal of Memory and Language, 33, 672-688.

Gilger, J. W., Pennington, B. F., \& DeFries, J. C. (1991). Risk for reading disability as a function of parental history in three family studies. Reading and Writing, 3, 205-217.

Gough, P. B., \& Tunmer, W. E. (1986). Decoding, reading, and reading disability. RASE: Remedial \& Special Education, 7(1), 6-10.

Hallgren, B. (1950). Specific dyslexia ("Congenital word blindness"): A clinical and genetic study. Acta Psychiatrica and Neurologica Scandinavica, 65, 1-287. 
Holopainen, L., Ahonen, T., \& Lyytinen, H. (2001). Predicting delay in reading achievement in a highly transparent language. Journal of Learning Disabilities, 34(5), 401-413.

Kaplan, E., Goodglass, H., \& Weintraub, S. (1983). The Boston Naming Test (2 ${ }^{\text {nd }}$ ed.). Philadelphia: Lea \& Febiger.

Karlsson, F. (1999). Finnish. An essential grammar. London: Routledge.

Korkman, M., Kirk, U., \& Kemp, S. (1998). NEPSY: A developmental neuropsychological assessment. San Antonio, TX: The Psychological Corporation.

Leach, J. M., Scarborough, H. S., \& Rescorla, L. (2003). Late-emerging reading disabilities. Journal of Educational Psychology, 95(2), 211-224.

Leppänen, U., Aunola, K., \& Nurmi, J. (2005). Beginning readers' reading performance and reading habits. Journal of Research in Reading, 28(4), 383-399.

Lerkkanen, M-K., Poikkeus, A-M., \& Ketonen, R. (in press). ARMI. Luku- ja kirjoitustaidon arviointimateriaali 1. luokalle. Helsinki: WSOY.

Lerkkanen, M-K., Rasku-Puttonen, H., Aunola, K., \& Nurmi, J. (2004). Reading performance and its developmental trajectories during the first and the second grade. Learning and Instruction, 14(2), 111-130.

Lindeman, J. (2000). Ala-asteen lukutesti: käyttäjän käsikirja. Oppimistutkimuksen keskus, Turun yliopisto.

Lonigan, C. J., Burgess, S. R., \& Anthony, J. L. (2000). Development of emergent literacy and early reading skills in preschool children: Evidence from a latent-variable longitudinal study. Developmental Psychology, 36, 596-613.

Lyon, G. R., Shaywitz, S. E., \& Shaywitz, B. A. (2003). A definition of dyslexia. Annals of Dyslexia, 53, 1-14.

Lyytinen, H., Ahonen, T., Eklund, K., Guttorm, T.K., Laakso, M.-L., Leinonen, S., Leppänen, P. H. T., Lyytinen, P., Poikkeus, A.-M., Puolakanaho, A., Richardson, U., \& 
Viholainen, H (2001). Developmental pathways of children with and without familial risk for dyslexia during the first years of life. Developmental Neuropsychology, 20, $535-554$.

Lyytinen, H., Aro, M., Eklund, K., Erskine, J., Guttorm, T.K., Laakso, M.-L., Leppänen, P.H.T., Lyytinen, P., Poikkeus, A.-M., Richardson, U., \& Torppa, M. (2004). The development of children at familial risk for dyslexia: birth to school age. Annals of Dyslexia, 54, 184-220.

Lyytinen, H., Aro, M., Holopainen, L., Leiwo, M., Lyytinen, P., \& Tolvanen, A. (2005). Children's language development and reading acquisition in a highly transparent orthography. In R. M. Joshi \& P. G. Aaron (Eds.), Handbook of orthography and literacy (pp. 47-62). Mahwah, NJ: Lawrence Erlbaum.

Lyytinen, H., Erskine, J., Tolvanen, A., Torppa, M., Poikkeus, A.-M., \& Lyytinen, P (2006). Trajectories of reading development: a follow-up from birth to school age of children with and without risk for dyslexia. Merrill-Palmer Quarterly, 52(3), 514-546.

Lyytinen, P. (1999). Varhaisen kommunikaation ja kielen kehityksen arviointimenetelmä (Finnish manual for the MacArthur Communicative Development Inventory, CDI). University of Jyväskylä, Child Research Center and Niilo Mäki Institute. Jyväskylä: Yliopistopaino.

Lyytinen, P., \& Lyytinen, H. (2004). Growth and predictive relations of vocabulary and inflectional morphology in children with and without familial risk for dyslexia. Applied Psycholinguistics, 25, $397-411$.

McCoach, D. B., O'Connell, A. A., Reis, S. M., \& Levitt, H. A. (2006). Growing readers: A hierarchical linear model of children's reading growth during the first 2 years of school. Journal of Educational Psychology, 98(1), 14-28. 
Muter, V., Hulme, C., Snowling, M. J., \& Stevenson, J. (2004). Phonemes, rimes, vocabulary, and grammatical skills as foundations of early reading development: Evidence from a longitudinal study. Developmental Psychology, 40(5), 665-681.

Muthén, L.K. \& Muthén, B.O. (1998-2003). Mplus user's guide. Los Angeles, CA: Author.

Muthén, B.O. (2001). Latent variable mixture modeling. In G. A. Marcoulides \& R.E. Schumacher (Eds.), Advanced structural equation modeling: New developments and techniques (pp. 1-33). Mahwah, NJ: Erlbaum.

Nation, K. (2005). Children's reading comprehension difficulties. In M. J. Snowling, \& C. Hulme (Eds.), The science of reading: A handbook. (pp. 248-265) Blackwell Publishing. Nation, K. (1999). Reading skills in hyperlexia: A developmental perspective. Psychological Bulletin, 125(3), 338-355.

Nation, K., Clarke, P., Marshall, C. M., \& Durand, M. (2004). Hidden language impairments in children: Parallels between poor reading comprehension and specific language impairment? Journal of Speech, Language, and Hearing Research, 47(1), 199-211.

Nation, K., Clarke, P., \& Snowling, M. J. (2002). General cognitive ability in children with reading comprehension difficulties. British Journal of Educational Psychology, 72(4), 549-560.

Nation, K., \& Norbury, C. F. (2005). Why reading comprehension fails: Insights from developmental disorders. Topics in Language Disorders, 25(1), 21-32.

Nation, K., \& Snowling, M. J. (2004). Beyond phonological skills: Broader language skills contribute to the development of reading. Journal of Research in Reading, 27(4), 342-356.

Nevala, J. \& Lyytinen, H. (2001). Sanaketjutesti. Jyväskylä: Niilo Mäki Instituutti ja Jyväskylän yliopiston Lapsitutkimuskeskus. 
Oakhill, J. V., Cain, K., \& Bryant, P. E. (2003). The dissociation of word reading and text comprehension: Evidence from component skills. Language and Cognitive Processes, 18(4), 443-468.

Olson, R. K., Datta, H., Gayan, J., \& DeFries, J. C. (1999). A behavioral-genetic analysis of reading disabilities and component processes. In R. M. Klein, \& P. A. McMullen (Eds.), Converging methods for understanding reading and dyslexia (pp. 133-153). Cambridge, MA: MIT Press.

Pennington, B. F., \& Lefly, D. L. (2001). Early reading development in children at family risk for dyslexia. Child Development, 72, 816-833.

Phillips, B. M., \& Lonigan, C. J. (2005). Social correlates of emergent literacy. In M. J. Snowling, \& C. Hulme (Eds.), The science of reading: A handbook. (pp. 173-187)Blackwell Publishing.

Porpodas, C. D. (1999). Patterns of phonological and memory processing in beginning readers and spellers of greek. Journal of Learning Disabilities, 32(5), 406-416.

Poskiparta, E., Niemi, P., Lepola, J., Ahtola, A., \& Laine, P. (2003). Motivational-emotional vulnerability and difficulties in learning to read and spell. British Journal of Educational Psychology, 73(2), 187-206.

Puolakanaho, A., Poikkeus, A-M., Ahonen, T., Tolvanen, A., \& Lyytinen, H. (2003). Assessment of three-and-a-half-year-old children's emerging phonological awareness in a computer animation context. Journal of Learning Disabilities, 36, 416-423.

Reynell, J., K., \& Huntley, M. (1987). Reynell Developmental Language Scales manual (2nd ed.). Windsor, UK: NFER - Nelson.

Roth, F. P., Speece, D. L., \& Cooper, D. H. (2002). A longitudinal analysis of the connection between oral language and early reading. Journal of Educational Research, 95(5), $259-272$. 
Rowan, B., Correnti, R., \& Miller, R. J. (2002). What large-scale, survey research tells us about teacher effects on student achievement: Insights from the prospects study of elementary schools. Teachers College Record, 104(8), 1525-1567.

Scarborough, H. S. (1990). Very early language deficits in dyslexic children. Child Development, 61, 1728-1743.

Scarborough, H. S. (2001). Connecting early language and literacy to later reading (dis)abilities: Evidence, theory and practice. In S. Neuman, \& D. Dickinson (Eds.), Handbook of Early Literacy Research (pp. 97-110). New York: Guilford Press.

Scarborough, H. S., \& Dobrich, W. (1994). On the efficacy of reading to preschoolers. Developmental Review, 14(3), 245-302.

Scarborough, H. S., Dobrich, W., \& Hager, M. (1991). Pre-school literacy experience and later reading achievement. Journal of Reading Disabilities, 24, 508-511.

Senechal, M., \& LeFevre, J. (2002). Parental involvement in the development of children's reading skill: A five-year longitudinal study. Child Development, 73(2), 445-460.

Seymour, P. H., Aro, M., \& Erskine, J. M. (2003). Foundation literacy acquisition in european orthographies. British Journal of Psychology, 94(2), 143-174.

Shankweiler, D., Lundquist, E., Katz, L., Stuebing, K. K., Fletcher, J. M., Brady, S., Fowler, A., Dreyer, L.G., Marchione, K.E., Shaywitz, S.E. \& Shaywitz, B.A. (1999). Comprehension and decoding: Patterns of association in children with reading difficulties. Scientific Studies of Reading, 3(1), 69-94.

Snow C. E., Burns, M. S., \& Griffin, P. (Eds.) (1998). Preventing Reading Difficulties in Young Children. Washington: National Academy Press.

Snowling, M. J., Gallagher, A., \& Frith, U. (2003). Family risk of dyslexia is continuous: Individual differences in the precursors of reading skill. Child Development, 74, 358373. 
Storch, S. A., \& Whitehurst, G. J. (2002). Oral language and code-related precursors to reading: Evidence from a longitudinal structural model. Developmental Psychology, 38(6), 934-947.

Stothard, S. E., \& Hulme, C. (1995). A comparison of phonological skills in children with reading comprehension difficulties and children with decoding difficulties. Journal of Child Psychology and Psychiatry, 36(3), 399-408.

Torppa, M., Poikkeus, A.-M., Laakso, M.-L., Leskinen, E., Tolvanen, A., Leppänen, P. H. T., Puolakanaho, A., Lyytinen, H. (submitted). Longitudinal associations between literacy environment, literacy interest, and phonological awareness and letter knowledge in children with and without familial risk of dyslexia.

Tunmer, W. E., \& Hoover, W. A. (1992). Cognitive and linguistic factors in learning to read. In P. B. Gough, L. C. Ehri \& R. Treiman (Eds.), Reading acquisition. (pp. 175214)Lawrence Erlbaum Associates, Inc.

Vellutino, F. V., Fletcher, J. M., Snowling, M. J., \& Scanlon, D. M. (2004). Specific reading disability (dyslexia): what we have learned in the past four decades. Journal of Child Psychology and Psychiatry, 45, 2-40.

Wechsler, D. (1989). Wechsler Preschool and Primary Scale of Intelligence-Revised. San Antonio, TX: The Psychological Corporation.

Wimmer, H., \& Mayringer, H. (2002). Dysfluent reading in the absence of spelling difficulties: A specific disability in regular orthographies. Journal of Educational Psychology, 94(2), 272-277.

Wimmer, H., Mayringer, H., \& Landerl, K. (2000). The double-deficit hypothesis and difficulties in learning to read a regular orthography. Journal of Educational Psychology, 92(4), 668-680. 
Wimmer, H., Mayringer, H., \& Landerl, K. (1998). Poor reading: A deficit in skill-automatization or a phonological deficit? Scientific Studies of Reading, 2(4), 321-340. 
Acknowledgements

The Jyvaskyla Longitudinal study of Dyslexia (JLD) belonged to the Finnish Center of Excellence Program (2000-2005) and was supported by the Academy of Finland, the Niilo Mäki Institute and the University of Jyväskylä, and the Finnish National Graduate School of Psychology. We would like to thank the families who participated in the study. Thank you also to Matthew Wuethrich for polishing the language 
TABLE 1. Skill Domains, Age of Assessment, and Standardized Alphas for Composite Scores and

Tasks

\begin{tabular}{|c|c|c|c|}
\hline Skill domain & $\begin{array}{l}\text { Age(s) of } \\
\text { assessment }\end{array}$ & $\begin{array}{l}\text { Composite mean } \\
\text { score standardized } \\
\text { alpha }\end{array}$ & Task(s) \\
\hline \multirow[t]{4}{*}{$\begin{array}{l}\text { 1. Receptive } \\
\text { language }\end{array}$} & $\begin{array}{l}14 \mathrm{~m} \\
18 \mathrm{~m}\end{array}$ & .78 & $\begin{array}{l}\text { Word comprehension, Finnish adaptation (CDI; Lyytinen, } \\
\text { P, 1999) of MacArthur Communicative Development } \\
\text { Inventory (CDI; Fenson et al., 1994). } \\
\text { Word comprehension, CDI. } \\
\text { Verbal comprehension, Reynell Developmental Language } \\
\text { Scales (RDLS; Reynell \& Huntley, 1987) }\end{array}$ \\
\hline & $2.5 \mathrm{y}$ & & Verbal comprehension, RDLS \\
\hline & $3.5 \mathrm{yr}$ & & $\begin{array}{l}\text { Receptive language, Peabody Picture Vocabulary (PPVT- } \\
\text { R; Dunn \& Dunn, 1981) }\end{array}$ \\
\hline & $5.0 \mathrm{yr}$ & & Receptive language, PPVT-R \\
\hline \multirow[t]{4}{*}{$\begin{array}{l}\text { 2. Expressive } \\
\text { language }\end{array}$} & $\begin{array}{l}12 \mathrm{~m} \\
14 \mathrm{~m} \\
18 \mathrm{~m}\end{array}$ & .93 & $\begin{array}{l}\text { Vocabulary production, CDI } \\
\text { Vocabulary production, CDI } \\
\text { Vocabulary production, CDI } \\
\text { Mastery of inflections, CDI } \\
\text { Maximum sentence length (mean number of morphemes } \\
\text { from } 3 \text { longest utterances), CDI } \\
\text { Expressive language items, RDLS }\end{array}$ \\
\hline & $\begin{array}{l}2.0 \mathrm{y} \\
2.5 \mathrm{y}\end{array}$ & .92 & $\begin{array}{l}\text { Vocabulary production, CDI } \\
\text { Mastery of inflections, CDI } \\
\text { Maximum sentence length, CDI } \\
\text { Vocabulary production, CDI } \\
\text { Mastery of inflections, CDI } \\
\text { Maximum sentence length, CDI } \\
\text { Expressive language, RDLS }\end{array}$ \\
\hline & $3.5 \mathrm{y}$ & & $\begin{array}{l}\text { Expressive language, Boston Naming Test (BNT; Kaplan, } \\
\text { Goodglass, \& Weintraub, 1983) }\end{array}$ \\
\hline & $5.5 \mathrm{y}$ & & Expressive language, BNT \\
\hline \multirow[t]{2}{*}{ 3. Morphology } & $3.5 \mathrm{y}$ & .57 & $\begin{array}{l}\text { Mastery of inflectional morphology (see Lyytinen et al., } \\
\text { 2001: Lyytinen \& Lyytinen, 2004) for adjectives, verbs } \\
\text { and nouns) }\end{array}$ \\
\hline & $5.0 \mathrm{y}$ & .76 & $\begin{array}{l}\text { Mastery of inflectional morphology (Lyytinen et al., } \\
\text { 2001: Lyytinen \& Lyytinen, 2004) }\end{array}$ \\
\hline \multirow[t]{3}{*}{ 4. Memory } & $3.5 \mathrm{y}$ & .67 & $\begin{array}{l}\text { Forward digit span (see Gathercole \& Adams, 1994) } \\
\text { Sentence repetition, Developmental Neuropsychological } \\
\text { Assessment (NEPSY; Korkman, Kirk, \& Kemp, 1998). }\end{array}$ \\
\hline & $\begin{array}{l}5.0 \mathrm{y} \\
5.5 \mathrm{y}\end{array}$ & .75 & $\begin{array}{l}\text { Digit span (computer presented) } \\
\text { Syllable span (computer presented) } \\
\text { Sentence repetition (NEPSY) } \\
\text { Nonword repetition (NEPSY) }\end{array}$ \\
\hline & $6.5 \mathrm{y}$ & & Digit span (computer presented) \\
\hline \multirow[t]{3}{*}{$\begin{array}{l}\text { 5. Rapid serial } \\
\text { naming }\end{array}$} & $3.5 \mathrm{y}$ & & $\begin{array}{l}\text { Rapid serial naming of objects RSN using RAN Rapid } \\
\text { Automatized Naming Test; see Denckla \& Rudel (1974, } \\
\text { 1976) }\end{array}$ \\
\hline & $5.5 \mathrm{y}$ & .80 & $\begin{array}{l}\text { RSN objects } \\
\text { RSN colors }\end{array}$ \\
\hline & $6.5 \mathrm{y}$ & .89 & $\begin{array}{l}\text { RSN objects } \\
\text { RSN colors } \\
\text { RSN numbers } \\
\text { RSN letters } \\
\end{array}$ \\
\hline 6. Letter knowledge & $3.5 \mathrm{y}$ & & $\begin{array}{l}\text { Letter naming (upper case fixed order) } \\
\text { Letter identification (from symbol distracters) }\end{array}$ \\
\hline
\end{tabular}




\begin{tabular}{|c|c|c|c|}
\hline & & .65 & $\begin{array}{l}\text { Word recognition (symbol string distracters) } \\
\text { Visual matching (matching letter string pairs) } \\
\text { Own name writing }\end{array}$ \\
\hline & $4.5 y$ & .72 & $\begin{array}{l}\text { Letter naming (upper case fixed order) } \\
\text { Letter identification } \\
\text { Word recognition } \\
\text { Visual matching } \\
\text { Own name writing }\end{array}$ \\
\hline & $5.0 \mathrm{y}$ & .66 & $\begin{array}{l}\text { Letter naming (upper case fixed order) } \\
\text { Word recognition } \\
\text { Visual matching }\end{array}$ \\
\hline & $5.5 y$ & .66 & $\begin{array}{l}\text { Letter naming (upper case fixed order) } \\
\text { Word recognition } \\
\text { Visual matching }\end{array}$ \\
\hline & $6.5 y$ & & Letter naming (lower case fixed order) \\
\hline \multirow[t]{4}{*}{$\begin{array}{l}\text { 7. Phonological } \\
\text { awareness }\end{array}$} & $3.5 y$ & .59 & $\begin{array}{l}\text { (for phonological measures, see Puolakanaho et al., 2003) } \\
\text { Word recognition (from picture choice) } \\
\text { Segment identification (of sub-word units) } \\
\text { Synthesis (of syllables and phonemes) } \\
\text { Continuation (from presented onset of word) } \\
\text { Phonological processing (NEPSY) }\end{array}$ \\
\hline & $4.5 y$ & .71 & $\begin{array}{l}\text { Segment identification } \\
\text { Synthesis } \\
\text { Continuation } \\
\text { Initial phoneme identification } \\
\text { Initial phoneme production }\end{array}$ \\
\hline & $5.5 y$ & .77 & $\begin{array}{l}\text { Segment identification } \\
\text { Synthesis } \\
\text { Initial phoneme identification } \\
\text { Initial phoneme production }\end{array}$ \\
\hline & $6.5 \mathrm{y}$ & .82 & $\begin{array}{l}\text { Segment identification } \\
\text { Synthesis } \\
\text { Initial phoneme identification } \\
\text { Initial phoneme production }\end{array}$ \\
\hline IQ measure & $5.0 \mathrm{y}$ and $8.0 \mathrm{y}$ & & $\begin{array}{l}\text { Wechsler Preschool and Primary Scales of Intelligence } \\
\text { (WPPSI-R; Wechsler, 1989); Verbal (vocabulary, } \\
\text { arithmetic, comprehension) and Performance (block } \\
\text { design, object assembly, picture completion) subtests. }\end{array}$ \\
\hline
\end{tabular}


Table 2. Correlation Matrix, Descriptive Statistics, and Intraclass Correlations for the Measures of Fluent Word Recognition and Reading Comprehension.

\begin{tabular}{|c|c|c|c|c|c|c|c|}
\hline & \multicolumn{4}{|c|}{ Fluent Word Recognition } & \multicolumn{3}{|c|}{ Reading Comprehension } \\
\hline & $\mathrm{T} 1$ & $\mathrm{~T} 2$ & T3 & $\mathrm{T} 4$ & $\mathrm{~T} 2$ & T3 & T4 \\
\hline \multicolumn{8}{|c|}{ Fluent Word Recognition } \\
\hline \multicolumn{8}{|l|}{$\mathrm{T} 1: 1^{\text {st }}$ grade fall } \\
\hline T2: $1^{\text {st }}$ grade spring & 0.82 & & & & & & \\
\hline $\mathrm{T} 3: 2^{\text {nd }}$ grade fall & 0.68 & 0.78 & & & & & \\
\hline T4: $2^{\text {nd }}$ grade spring & 0.67 & 0.78 & 0.81 & & & & \\
\hline \multicolumn{8}{|l|}{ Reading comprehension } \\
\hline $\mathrm{T} 2: 1^{\text {st }}$ grade spring & 0.57 & 0.64 & 0.55 & 0.52 & & & \\
\hline T3: $2^{\text {nd }}$ grade fall & 0.48 & 0.52 & 0.47 & 0.46 & 0.53 & & \\
\hline T4: $2^{\text {nd }}$ grade spring & 0.43 & 0.44 & 0.40 & 0.42 & 0.52 & 0.56 & \\
\hline Range & $0-16$ & $.80-16$ & $.50-33$ & $4.50-31$ & $0-24$ & $0-12$ & $0-12$ \\
\hline Mean & 5.22 & 8.80 & 13.90 & 14.91 & 14.33 & 7.83 & 8.79 \\
\hline SD & 3.44 & 3.54 & 4.51 & 4.38 & 7.30 & 2.63 & 2.55 \\
\hline $\mathrm{N}$ & 1520 & 1520 & 1562 & 1526 & 1518 & 1555 & 1503 \\
\hline Intraclass Correlation & .05 & .07 & .10 & .09 & .04 & .06 & .05 \\
\hline
\end{tabular}

Note. For all correlation coefficients p-value $<.001$ 
Table 3. Descriptive Statistics of the Observed Variables and Their Mean Comparisons

\begin{tabular}{|c|c|c|c|c|c|c|c|c|c|c|}
\hline & \multicolumn{3}{|c|}{ At-risk (AR) } & \multicolumn{3}{|c|}{ Control (CO) } & \multicolumn{3}{|c|}{ Classmates (CM) } & \multirow[b]{2}{*}{ Group comparisons } \\
\hline & $\mathrm{N}$ & $\mathrm{M}$ & $\mathrm{sd}$ & $\mathrm{N}$ & $\mathrm{M}$ & $\mathrm{sd}$ & $\mathrm{N}$ & $\mathrm{M}$ & $\mathrm{sd}$ & \\
\hline \multicolumn{11}{|l|}{$\underline{\text { Fluent Word Recognition }}$} \\
\hline $\mathrm{T} 1: 1^{\mathrm{st}}$ grade fall & 100 & 4.33 & 3.31 & 84 & 6.71 & 4.17 & 1336 & 5.19 & 3.39 & $\mathrm{AR}<\mathrm{CM}<\mathrm{CO}$ \\
\hline $\mathrm{T} 2: 1^{\text {st }}$ grade spring & 101 & 7.62 & 3.62 & 87 & 9.91 & 3.96 & 1332 & 8.82 & 3.48 & $\mathrm{AR}<\mathrm{CM}<\mathrm{CO}$ \\
\hline $\mathrm{T} 3: 2^{\text {nd }}$ grade fall & 98 & 12.68 & 4.71 & 80 & 14.83 & 4.62 & 1384 & 13.94 & 4.48 & $\mathrm{AR}<\mathrm{CM}=\mathrm{CO}$ \\
\hline $\mathrm{T} 4: 2^{\text {nd }}$ grade spring & 99 & 13.57 & 4.51 & 76 & 15.51 & 4.74 & 1351 & 14.97 & 4.33 & $\mathrm{AR}<\mathrm{CM}=\mathrm{CO}$ \\
\hline \multicolumn{11}{|l|}{$\underline{\text { Reading comprehension }}$} \\
\hline T2: Sentences $1^{\text {st }}$ grade spring & 101 & 12.21 & 8.05 & 86 & 16.47 & 6.79 & 1331 & 14.35 & 7.24 & $\mathrm{AR}<\mathrm{CM}<\mathrm{CO}$ \\
\hline T3: Text $2^{\text {nd }}$ grade fall & 93 & 7.20 & 3.15 & 78 & 8.74 & 2.22 & 1284 & 7.82 & 2.61 & $\mathrm{AR}=\mathrm{CM}<\mathrm{CO}$ \\
\hline T4: Text $2^{\text {nd }}$ grade spring & 97 & 8.67 & 3.11 & 73 & 9.29 & 2.20 & 1333 & 8.77 & 2.52 & $\mathrm{AR}=\mathrm{CM}=\mathrm{CO}$ \\
\hline
\end{tabular}

Note. In group comparisons pairwise Bonferroni corrected values were used, $\mathrm{p}<.05$ 
Table 4. Indices for Mixture Models with Different Numbers of Latent Classes

\begin{tabular}{|c|c|c|c|c|c|c|c|c|c|}
\hline $\begin{array}{c}\text { Number of } \\
\text { Classes }\end{array}$ & $\log \mathrm{L}$ & $\mathrm{ABIC}$ & AIC & $\begin{array}{c}\text { VLMR } \\
\text { (p-value) }\end{array}$ & $\begin{array}{c}\mathrm{n} \\
(\text { class 1) }\end{array}$ & $\begin{array}{c}\mathrm{n} \\
\text { (class 2) }\end{array}$ & $\begin{array}{c}\mathrm{n} \\
(\text { class 3) }\end{array}$ & $\begin{array}{c}\mathrm{n} \\
(\text { class 4) }\end{array}$ & $\begin{array}{c}\mathrm{n} \\
(\text { class 5) }\end{array}$ \\
\hline 1 & -11836.541 & 23776.054 & 23721.083 & & 1750 & & & & \\
\hline 2 & -11642.895 & 23423.084 & 23349.789 & .000 & 1512 & 238 & & & \\
\hline 3 & -11510.557 & 23192.733 & 23101.114 & .000 & 343 & 1178 & 229 & & \\
\hline 4 & -11429.005 & 23063.953 & 22954.011 & .004 & 636 & 330 & 646 & 138 & \\
\hline 5 & -11342.880 & 22926.033 & 22797.760 & .049 & 435 & 228 & 722 & 173 & 192 \\
\hline
\end{tabular}

Note. ABIC = Sample-Size Adjusted Bayesian Information Criteria; VLMR = Vuong-Lo-Mendell-Rubin test 
Table 5. Descriptive Statistics of Reading Development in the Five Reading Subtypes

\begin{tabular}{|c|c|c|c|c|c|c|c|c|c|c|c|}
\hline & \multicolumn{2}{|c|}{ Good readers (GR) } & \multicolumn{2}{|c|}{$\begin{array}{l}\text { Average Readers } \\
\text { (AR) }\end{array}$} & \multicolumn{2}{|r|}{$\begin{array}{l}\text { Slow Readers } \\
\text { (SR) }\end{array}$} & \multicolumn{2}{|c|}{$\begin{array}{l}\text { Poor Comprehenders } \\
\text { (PC) }\end{array}$} & \multicolumn{2}{|r|}{$\begin{array}{l}\text { Poor Readers } \\
\quad \text { (PR) }\end{array}$} & \multirow{2}{*}{$\begin{array}{l}\text { Reading type Mean } \\
\text { Comparisons }\end{array}$} \\
\hline & $\mathrm{N}$ & M (s.e.) & $\mathrm{N}$ & M (s.e.) & $\mathrm{N}$ & M (s.e.) & $\mathrm{N}$ & M (s.e.) & $\mathrm{N}$ & M (s.e.) & \\
\hline \multicolumn{12}{|l|}{ Fluent Word Recognition } \\
\hline $\mathrm{T} 1: 1^{\text {st }}$ grade fall & 181 & $12.23(.09)$ & 628 & $5.48(.08)$ & 381 & $3.16(.10)$ & 147 & $4.20(.18)$ & 179 & $2.50(.12)$ & $\mathrm{PR}<\mathrm{SL}<\mathrm{PC}<\mathrm{AR}<\mathrm{GR}$ \\
\hline $\mathrm{T} 2: 1^{\text {st }}$ grade spring & 175 & $14.06(.09)$ & 628 & $9.68(.11)$ & 383 & $6.72(.13)$ & 149 & $8.88(.21)$ & 180 & $5.15(.15)$ & $\mathrm{PR}<\mathrm{SL}<\mathrm{PC}<\mathrm{AR}<\mathrm{GR}$ \\
\hline $\mathrm{T} 3: 2^{\text {nd }}$ grade fall & 175 & $20.21(.11)$ & 659 & $14.78(.13)$ & 368 & $11.37(.19)$ & 164 & $14.75(.25)$ & 194 & $9.43(.21)$ & $\mathrm{PR}<\mathrm{SL}<\mathrm{PC}=\mathrm{AR}<\mathrm{GR}$ \\
\hline T4: $2^{\text {nd }}$ grade spring & 164 & $21.04(.11)$ & 648 & $15.78(.13)$ & 360 & $12.73(.18)$ & 160 & $15.17(.28)$ & 192 & $10.67(.21)$ & $\mathrm{PR}<\mathrm{SL}<\mathrm{PC}=\mathrm{AR}<\mathrm{GR}$ \\
\hline \multicolumn{12}{|l|}{$\underline{\text { Reading comprehension }}$} \\
\hline T2: Sentences $1^{\text {st }}$ grade spring & 173 & $20.82(.30)$ & 630 & $19.66(.13)$ & 384 & $6.99(.18)$ & 148 & $15.16(.25)$ & 178 & $4.48(.25)$ & $\mathrm{PR}<\mathrm{SL}<\mathrm{PC}<\mathrm{AR}<\mathrm{GR}$ \\
\hline T3: Text $2^{\text {nd }}$ grade fall & 173 & $10.22(.13)$ & 658 & $8.81(.08)$ & 360 & $6.81(.13)$ & 163 & $6.99(.18)$ & 199 & $5.09(.16)$ & $\mathrm{PR}<\mathrm{SL}=\mathrm{PC}<\mathrm{AR}<\mathrm{GR}$ \\
\hline T4: Text $2^{\text {nd }}$ grade spring & 161 & $10.75(.11)$ & 627 & $10.21(.05)$ & 356 & $9.10(.07)$ & 158 & $6.18(.09)$ & 199 & $4.28(.11)$ & $\mathrm{PR}<\mathrm{PC}<\mathrm{SL}<\mathrm{AR}<\mathrm{GR}$ \\
\hline
\end{tabular}


Table 6. Crosstabulation of the Reading Subtypes by Study Groups (Frequencies in Parentheses)

\begin{tabular}{llll}
\hline & Classmates & JLD at-risk group & JLD control group \\
\hline Good readers $(\mathrm{n}=192)$ & $10.5 \%(164)$ & $9.6 \%(10)$ & $20.7 \%(18)$ \\
Average readers $(\mathrm{n}=722)$ & $41.8 \%(652)$ & $31.7 \%(33)$ & $42.5 \%(37)$ \\
Slow readers $(\mathrm{n}=435)$ & $24.6 \%(384)$ & $35.6 \%(37)$ & $16.1 \%(14)$ \\
Poor comprehenders $(\mathrm{n}=173)$ & $10.1 \%(157)$ & $5.8 \%(6)$ & $11.5 \%(10)$ \\
Poor readers $(\mathrm{n}=228)$ & $13.0 \%(202)$ & $17.3 \%(18)$ & $9.2 \%(8)$ \\
Total & 1559 & 104 & 87 \\
\hline
\end{tabular}




\section{Figure Captions}

Figure 1. Latent factor model of reading comprehension and fluent word recognition development during $1^{\text {st }}$ and $2^{\text {nd }}$ grade. Standardized estimates.

Figure 2. Mean reading skill profiles of the reading subtypes identified with mixture modeling

Figure 3. Early developmental skill profiles of the reading subtypes among the JLD participants (n =191)

Figure 4. Reading experience profiles of the reading subtypes among the JLD participants $(\mathrm{n}=$ 191) 


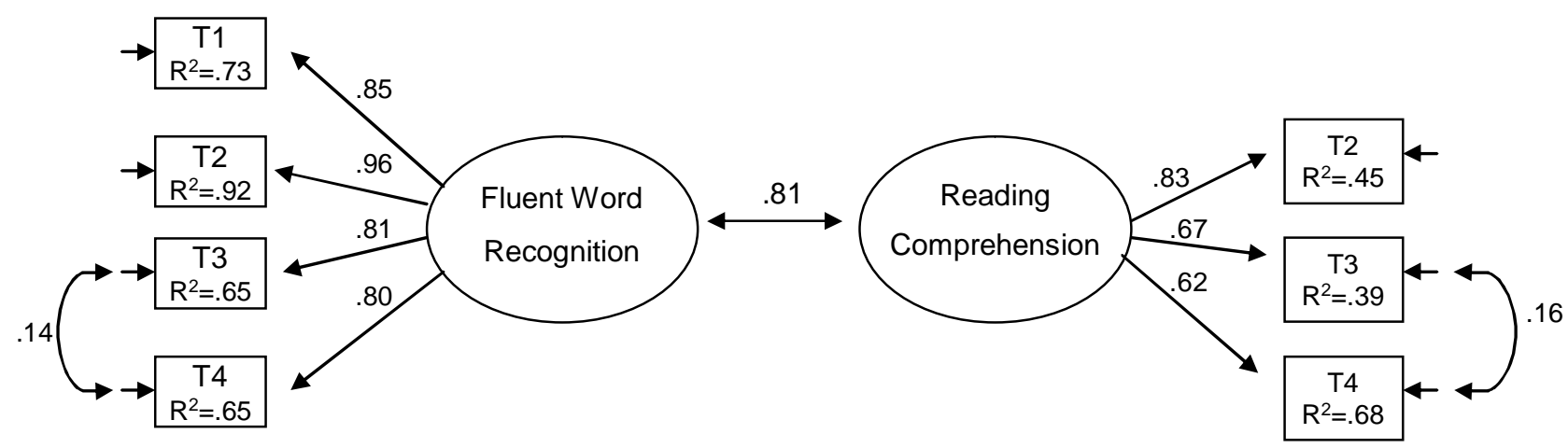

Figure 1. 


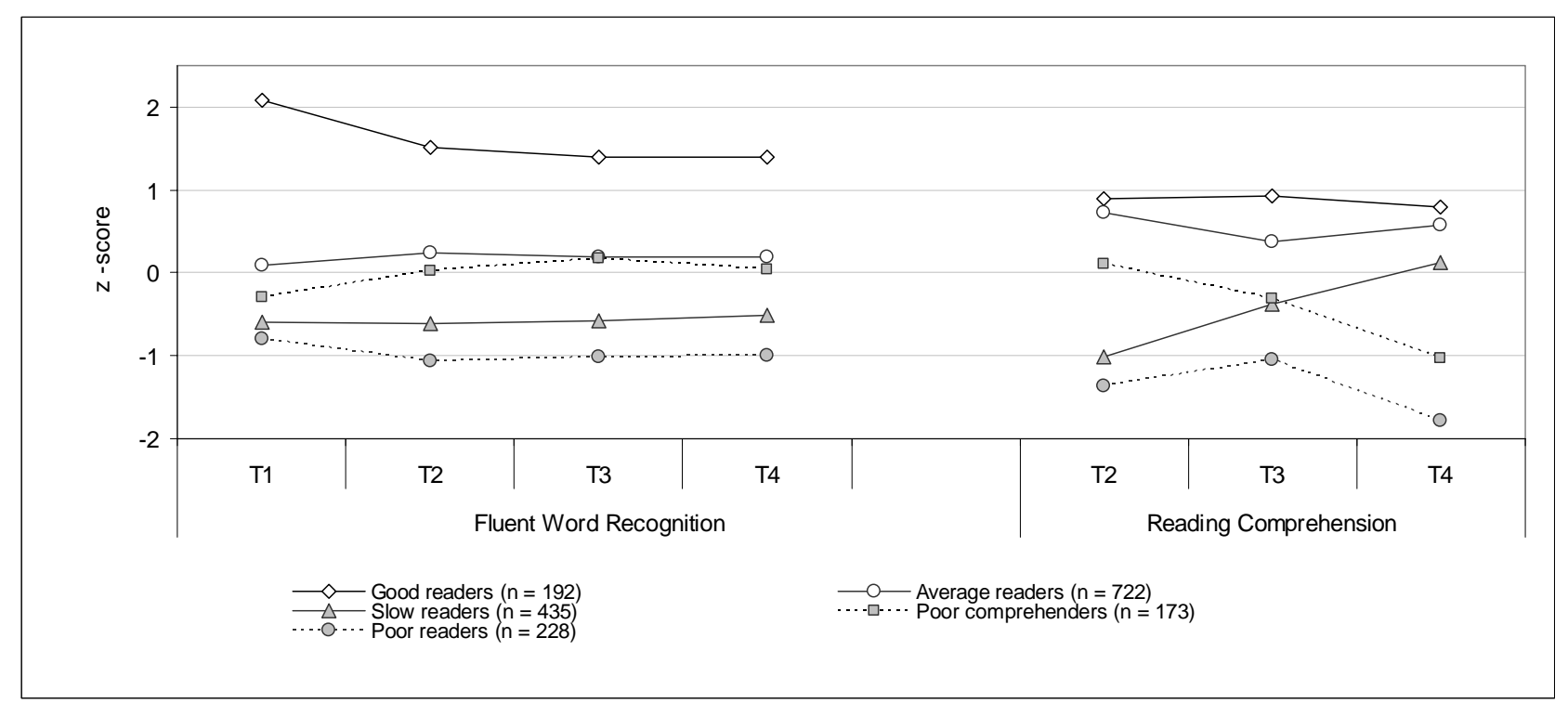

Note. The sample size within reading subtypes varied in time points and was for Good readers 161-175, for Average readers 627-659, for Slow readers 356-384, for Poor comprehenders 147-164, and for Poor readers 178-199 because of missing data.

Figure 2. 


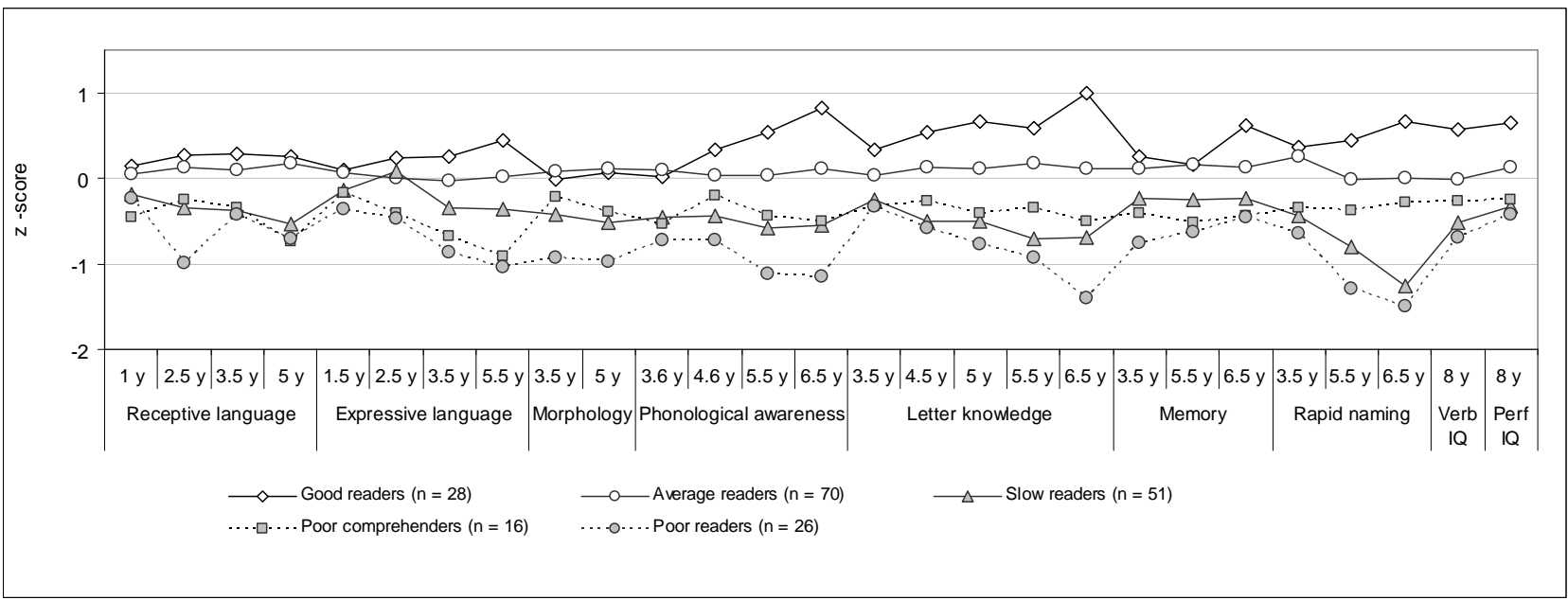

Note. The sample size within reading types varied in time points and was for Good readers 24-28, for Average readers 63-70, for Slow readers 41-51, for Poor comprehenders 11-16, and for Poor readers 18-26.

\section{Figure 3.}




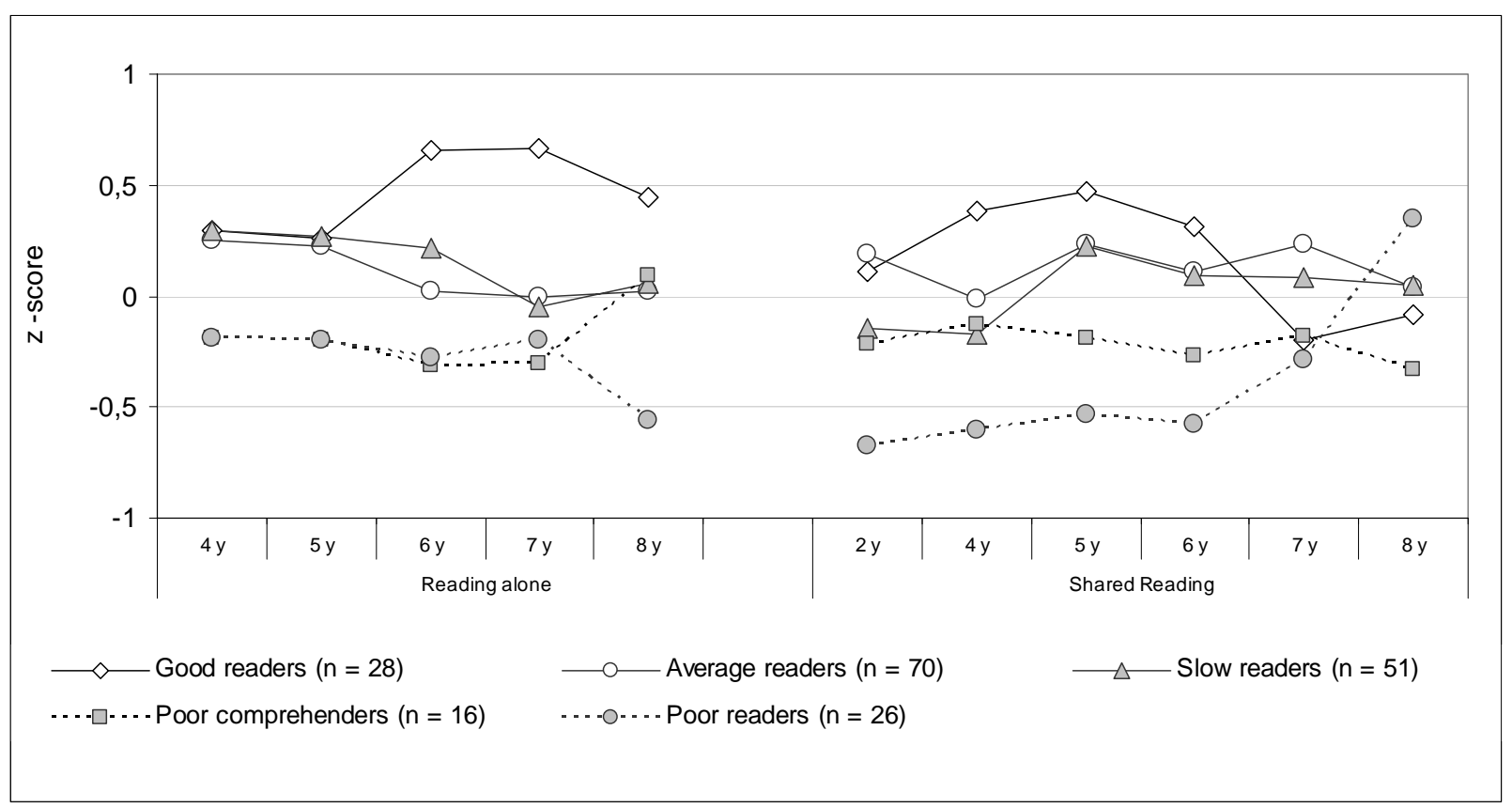

Note. The sample size within reading types varied in time points and was for Good readers 24-27, for Average readers 58-70, for Slow readers 40-51, for Poor comprehenders 13-16, and for Poor readers 19-26.

Figure 4. 